\title{
Selective review and commentary on emerging pharmacotherapies for opioid addiction
}

This article was published in the following Dove Press journal:

Substance Abuse and Rehabilitation

27 October 2011

Number of times this article has been viewed

\author{
Walter Ling' \\ Larissa Mooney' \\ Min Zhao ${ }^{2}$ \\ Suzanne Nielsen' \\ Matthew Torrington' \\ Karen Miotto' \\ 'Integrated Substance Abuse \\ Programs, University of California, \\ Los Angeles, CA, USA; ${ }^{2}$ Shanghai \\ Mental Health Center, Shanghai Jiao \\ Tong University School of Medicine, \\ Shanghai, China
}

\begin{abstract}
Pharmacotherapies for opioid addiction under active development in the US include lofexidine (primarily for managing withdrawal symptoms) and Probuphine ${ }^{\circledR}$, a distinctive mode of delivering buprenorphine for six months, thus relieving patients, clinicians, and regulatory personnel from most concerns about diversion, misuse, and unintended exposure in children. In addition, two recently approved formulations of previously proven medications are in early phases of implementation. The sublingual film form of buprenorphine + naloxone (Suboxone ${ }^{\circledR}$ ) provides a less divertible, more quickly administered, more child-proof version than the buprenorphine + naloxone sublingual tablet. The injectable depot form of naltrexone $\left(\right.$ Vivitrol $\left.^{\circledR}\right)$ ensures consistent opioid receptor blockade for one month between administrations, removing concerns about medication compliance. The clinical implications of these developments have attracted increasing attention from clinicians and policymakers in the US and around the world, especially given that human immunodeficiency virus/acquired immunodeficiency syndrome and other infectious diseases are recognized as companions to opioid addiction, commanding more efforts to reduce opioid addiction. While research and practice improvement efforts continue, reluctance to adopt new medications and procedures can be expected, especially considerations in the regulatory process and in the course of implementation. Best practices and improved outcomes will ultimately emerge from continued development efforts that reflect input from many quarters.
\end{abstract}

Keywords: buprenorphine, naltrexone, probuphine, lofexidine, implant buprenorphine, buprenorphine film

\section{Introduction}

In late 2011, the only medications for opioid addiction under active development in the US are lofexidine (licensed as Britlofex ${ }^{\circledR}$ in the UK, primarily for detoxification) and depot buprenorphine as Probuphine ${ }^{\circledR}$. The development of Probuphine is a testament to the clinical success of sublingual buprenorphine; there would have been no Probuphine development had buprenorphine been a clinical failure. The need for the long-acting formulation is also an indication of the concerns about medication nonadherence and the potential for diversion of sublingual buprenorphine. Lofexidine is an $\alpha 2$-adrenergic receptor agonist that has been approved for opioid withdrawal in the UK and used for almost two decades, but it is not yet approved for that indication in the US. Because lofexidine is not an opioid, it is politically attractive and socially more palatable, but its clinical viability remains in question. In addition to its potential role in opioid detoxification, lofexidine may turn out to be useful for buprenorphinemaintained patients desiring to taper and discontinue buprenorphine.
Integrated Substance Abuse Programs,

Department of Psychiatry

and Biobehavioral Sciences,

David Geffen School of Medicine

at UCLA, 1640 S Sepulveda Blvd,

Suite I20, Los Angeles,

CA $90025-7535$, USA

Tel +I 3102675888

$\mathrm{Fax}+\mathrm{I} 3103120552$

Email Iwalter@ucla.edu
(C) 20I I Ling et al, publisher and licensee Dove Medical Press Ltd. This is an Open Access article which permits unrestricted noncommercial use, provided the original work is properly cited. 
A recent addition to the armamentarium for opioid addiction is the injectable depot formulation of the opioid antagonist naltrexone, marketed as Vivitrol ${ }^{\circledR}$. Approved by the US Food and Drug Administration in October 2010 for opioid addiction, so technically beyond the development stage, Vivitrol is included in this review because its clinical utility is yet to be fully explicated, with only one full-scale trial to document its use for opioid addiction. ${ }^{1}$ We also discuss the sublingual film form of buprenorphine combined with naloxone, marketed as Suboxone ${ }^{\circledR}$, recently made available in an effort to provide a less divertible, more child-proof version than the buprenorphine + naloxone tablet. The clinical implications of these developments for treatment of opioid addiction have attracted increasing attention from clinicians and policymakers in the US and around the world, especially as human immunodeficiency virus (HIV)/acquired immunodeficiency syndrome (AIDS) and other infectious diseases are recognized as close companions to opioid addiction, driving more efforts to reduce opioid addiction and its consequences.

\section{Lofexidine}

Lofexidine is an antihypertensive medication that has also been used in Britain and elsewhere for reducing opioid withdrawal symptoms. Research has found that lofexidine is useful in managing opioid withdrawal symptoms during detoxification from heroin and methadone, as documented in two Cochrane reviews. ${ }^{2,3}$ Based on the meta-analyses, the authors concluded that "lofexidine has a better safety profile than clonidine", a similar medication with a longer history of off-label use in managing opioid withdrawal in the US and elsewhere, but one that often causes hypotension, sedation, and risk of rebound hypertension. A more recent review ${ }^{4}$ confirmed the less frequent incidence and lower severity of adverse events with lofexidine, particularly in terms of hypotension, in comparison with clonidine $\left(\right.$ Catapress $^{\circledR}$ ) used for opioid detoxification. Those reviews confirmed earlier work examining five trials in which safety, efficacy, and tolerability of lofexidine were found superior to clonidine. ${ }^{5}$ One of the studies was notable for its inclusion of heroin addicts not previously stabilized, among whom dropout from lofexidine was greater than in the other trials of opioid-maintained patients. ${ }^{6}$

In another study designed to determine the efficacy of lofexidine as a detoxification medication, investigators enrolled 68 opioid addicts (on heroin, morphine, or hydromorphone) who were then stabilized for 3 days on a fixed dose of morphine followed by either 5 days of lofexidine or placebo by random assignment. ${ }^{7}$ With better retention and with significantly fewer and less severe withdrawal symptoms among the lofexidine group, the trial was halted on ethical grounds. Side effects associated with lofexidine included dizziness, hypotension, lassitude, and insomnia. Findings from that research in the US were also consistent with the earlier reviews ${ }^{5}$ of lofexidine trials in Taiwan and in Britain, where lofexidine has been approved since 1992 for opioid withdrawal treatment.

Being a nonopioid makes lofexidine a promising candidate in medication development efforts, especially considering its ability to reduce withdrawal symptoms safely with fewer side effects than clonidine and with efficacy that is comparable with opioid agonist or partial agonist medications (methadone, buprenorphine) sometimes used in detoxification. To move lofexidine forward in the US, the manufacturer's licensee (US World Meds Inc) has proposed research to be conducted in a cooperative agreement arrangement with the US National Institute on Drug Abuse to replicate findings confirming the effectiveness of lofexidine in reducing opioid withdrawal symptoms. In accord with the position of the US Food and Drug Administration, the research would likely emphasize additional assessment of withdrawal symptoms according to subjective measures, eg, the Short Opiate Withdrawal Scale ${ }^{8}$ or the Clinical Opiate Withdrawal Scale, ${ }^{9,10}$ instead of the Modified Himmelsbach Opioid Withdrawal Scale, as used by Yu et al. ${ }^{7}$

\section{Probuphine: buprenorphine implant Buprenorphine for opioid addiction}

Buprenorphine is a partial $\mathrm{mu}$ opioid receptor agonist approved by the US Food and Drug Administration (FDA) in October, 2002 as a pharmacotherapy for the treatment of opioid addiction. ${ }^{11}$ Controlled clinical trials in several thousand patients over the past 15 years have provided strong support for its therapeutic efficacy. ${ }^{12-17}$ Suboxone, a sublingual combination tablet containing buprenorphine and naloxone (an opioid antagonist) was developed to mitigate injection use.

As an office-based pharmacotherapy, buprenorphine allows patients to receive medication by prescription to be taken at home, thereby avoiding daily attendance at a traditional opioid treatment program. Buprenorphine has been well received in the US, Australia, and Europe, increasing the number of patients seeking treatment for opioid addiction because of its availability at private physicians' offices, its less restrictive controls, and its favorable safety profile. ${ }^{16-20}$ Compared with full mu agonists, buprenorphine has the advantage of limited dose-dependent euphoria and less respiratory depression at higher doses because of the ceiling effect. 
In 2007, more than two million prescriptions for buprenorphine were issued to about 300,000 patients in the US, and more than 14,000 physicians have been authorized to prescribe buprenorphine for opioid addiction. ${ }^{21}$ This compares with about 268,000 patients in 2008 on daily methadone, which was introduced 40 years ago. As evidenced by its proven efficacy, its widespread uptake by clinicians, and its acceptance among patients, buprenorphine looks to be a success. It is arguably the most significant advance in the treatment of opioid addiction since the introduction of methadone. Buprenorphine is not an unqualified success, however, because the successful adoption of the sublingual tablet formulation has come with its own price, ie, diversion, misuse, inconsistent compliance, and accidental poisoning from unintended exposure. Seeking to enhance effective delivery and to counter some of these problems, advances in medication development led to the development of other preparations, ie, the film and implant forms of buprenorphine (Probuphine).

\section{Probuphine}

The Probuphine form of buprenorphine employs the ProNeura long-term drug delivery system, ${ }^{22}$ consisting of a small, solid "rod" made from a mixture of ethylene vinyl acetate and the equivalent of about $80 \mathrm{mg}$ of buprenorphine, reliably released at a measured rate according to the matrix diffusion. The rod is placed subdermally in the upper arm in a 15-minute, procedure in the office, and is removed in a similar manner at the end of the treatment period. Probuphine eliminates the need for daily dosing and reliably provides a sustained and constant blood concentration lasting through six months, thereby reducing or eliminating use of illicit opioids. The standard implant dose, following the manufacturer's brochure, is four rods, with a fifth and sixth rod added if additional medication is needed according to the physician's assessment. Patients are first inducted onto sublingual buprenorphine for 3-7 days in preparation for the implant of Probuphine rods.

Research has documented the safety and acceptability of the transition from sublingual buprenorphine to the Probuphine implant formulation. ${ }^{22}$ In a six-month placebocontrolled trial involving 163 patients randomized 2:1 (Probuphine:placebo), the study showed that patients assigned to Probuphine implants, compared with those assigned to placebo, had less illicit opioid use over weeks 1-16, 17-24, and $1-24 .{ }^{23}$ The Probuphine group also had better retention, fewer withdrawal symptoms, lower craving scores, and better global clinical improvement by patient and investigator assessments. With Probuphine's depot delivery providing reliable pharmacotherapeutic effects over a six-month period, medication compliance is assured and medication diversion or misuse is eliminated.

Preliminary findings were recently released from a Phase III study of Probuphine confirming the safety and efficacy, comparing Probuphine with placebo and with active drug (Suboxone) over a 24 -week period. ${ }^{24}$ Statistically significant results were found for the two primary endpoints, ie, percentages of urine samples testing negative for illicit opioid use over the 24 -week treatment period $(P<0.0001)$, and congruence of urine toxicology with patient self-reported opioid use $(P<0.0001)$. Notably, Probuphine efficacy was confirmed as noninferior to the Suboxone form of buprenorphine at $12-16 \mathrm{mg} /$ day.

Research continues in order to collect the additional data necessary for the submission of a New Drug Application to the FDA. Topics of interest in future research include the need for additional rods to be implanted if dosage does not appear to alleviate withdrawal symptoms entirely, and the issue of taper from buprenorphine once the implants have been removed, depending on remaining blood levels of buprenorphine and potential for withdrawal.

\section{Vivitrol: injectable, extended-release naltrexone Naltrexone, an effective but underutilized medication}

For three decades, the opioid antagonist, naltrexone $\left(\mathrm{ReVia}^{\circledR}\right)$, has been demonstrated to be a safe and effective orally administered pharmacotherapy for opioid addiction..$^{25-32}$ Naltrexone and its active metabolite, 6- $\beta$-naltrexol, are competitive antagonists at the mu opioid receptors, which is the mechanism of action for the management of opioid addiction. Naltrexone blockade or attenuation of the reinforcing effects of subsequently administered opioids theoretically leads to extinction of opioid-taking behaviors over time, aided by behavioral therapy. Naltrexone is not addictive, affords no agonist effects, and is not sedating.

The pharmacologic efficacy of naltrexone has not yielded commensurate clinical success for treatment of opioid addiction because of poor patient compliance and high rates of treatment dropout. ${ }^{33}$ In a trial of three times weekly naltrexone for heroin addiction, only 10 of 108 enrolled patients remained in treatment for 14 weeks, and 74 either never started dosing or had so few doses that no blockade was in effect. ${ }^{34}$ Furthermore, noncompliance and patient-initiated termination of naltrexone therapy have been associated with opioid overdose, and at a rate higher than occurs with 
methadone treatment, ${ }^{35-37}$ possibly due to decreased tolerance or receptor supersensitivity following prolonged opioid receptor blockade. Improved compliance has been noted in certain highly motivated subsamples of opioid addicts, ${ }^{38-41}$ as well in programs that include psychosocial therapy, ${ }^{42,43}$ including contingency management. ${ }^{44,45}$

To counter the problems of compliance and premature discontinuation typical of oral naltrexone, development of depot naltrexone (by implant and by injection) represents an important advance in the treatment of opioid dependence. As demonstrated in work to determine clinical dosing by Comer et al, ${ }^{46-48} 384 \mathrm{mg}$ naltrexone delivered in sustained-release depot formulation blocked the reinforcing, subjective, and physiological effects of up to $25 \mathrm{mg}$ heroin, and provided therapeutic plasma levels for approximately 30 days. ${ }^{49-51}$ Importantly, at this dose, naltrexone resulted in better than $80 \%$ retention in treatment at six weeks versus $40 \%$ for placebo. ${ }^{48}$ In comparison with the oral formulation, depot naltrexone showed significantly higher rates of abstinence and better treatment outcomes at 12-month follow-up. ${ }^{52}$ Adverse events were minimal and limited to local responses at the injection site..$^{53}$

\section{Extended-release injectable formulation}

First approved for treatment of alcohol abuse, Vivitrol is an extended-release formulation of naltrexone injected once monthly (every four weeks), with peak drug concentrations occurring at 2 hours and again at 2-3 days. Concentrations slowly decline after 14 days, remaining at therapeutic levels through 30 days, with metabolites continuing to be detectable after one month. The most common adverse events associated with Vivitrol in clinical trials were nausea, vomiting, headache, dizziness, asthenic conditions, and injection site reactions. In addition to possible hepatic toxicity, naltrexone and other opioid receptor antagonists used over the long term can increase sensitivity of the opioid receptors, which continues for some duration following cessation. An increased potential thereby exists for overdose in the case of illicit use of opioids following cessation of long-term naltrexone therapy. In the event of need for opioid pain medication, the manufacturer recommends regional analgesia or the use of nonopioids.

The Vivitrol extended-release formulation has been found safe and well tolerated for participants in studies of alcoholics $^{54-56}$ and was approved for this indication by the FDA in 2006. Other research found that $384 \mathrm{mg}$ of extendedrelease naltrexone resulted in "minimal and generally mild" adverse events and that the formulation was "well tolerated" by combination opioid and stimulant users. ${ }^{48}$
A randomized, placebo-controlled, double-blind trial of Vivitrol was conducted in Russia, where agonist replacement therapy is not available. ${ }^{1}$ Participants were first detoxified in inpatient settings for less than 30 days to ensure at least 7 days of opioid abstinence. Participants received monthly intramuscular injections of Vivitrol $380 \mathrm{mg}(\mathrm{n}=126)$ or placebo ( $\mathrm{n}=124)$ for four months with 12 biweekly counseling sessions. The number of weeks of confirmed abstinence based on rate of opioid-negative urine drug tests and self-report of nonuse during weeks 5-24 was the primary outcome. In the Vivitrol group, a median $90 \%$ confirmed abstinent weeks during weeks 5-24 versus 35\% for placebo $(P=0.0002)$. More opioid-free days were reported by the Vivitrol participants ( $P=0.0004 ; 99.2 \%$ versus $60.4 \%$ of placebo participants). Vivitrol participants were retained in the study more than 168 days on average compared with 96 days for placebo participants $(P=0.0042)$. Craving was reduced $50 \%$ from baseline levels in the Vivitrol group, whereas there was no change in the placebo group. No Vivitrol participants died, overdosed, or ended participation due to severe adverse events associated with the study protocol.

\section{Buprenorphine sublingual film}

The manufacturer of Suboxone (Reckitt Benckiser Pharmaceuticals, Richmond, VA) gained FDA approval in August 2010 for its buprenorphine film designed to reduce diversion and to reverse the troubling rise in unintentional exposure in children. The US Drug Abuse Warning System documented that $94 \%$ of presentations to emergency departments for accidental ingestion of buprenorphine in 2009 involved children under the age of six years. ${ }^{57}$ The Suboxone and Subutex ${ }^{\circledR}$ tablet formulations may appear similar to candy, as hypothesized in recent literature to be a factor in the high rate of accidental ingestion by children. ${ }^{58}$ More than $95 \%$ of accidental child exposures result from parental carelessness with the handling of their medications, primarily from not properly storing the medication away from children. It is unclear whether the widely held perception of buprenorphine's general safety may contribute to carelessness with medication storage and handling. The safety of the film strip has been tested for the Consumer Product Safety Commission, showing that one child out of 50 was able to open two or more of the film pouches. ${ }^{59}$

The key features of the film are that it is less prone to ingestion by young children because of its restrictive packaging, it is clinically interchangeable with the sublingual tablet forms, and is more quickly dissolved and better tasting, so is acceptable to patients familiar with the tablet form. The film packaging contains unique identifier information in barcode format, 
allowing authorities to track sourcing of diverted supplies. Furthermore, the interchangeability has allowed a continuity of practice in terms of dosage during treatment. In many countries (eg, Australia, UK), supervised dosing is required, at least at the start of treatment, so the reduced dosing time of the film means less supervision required by clinical staff. Still, the film can be considered only a partial success at this point after being made available in October 2010. Patient preference for the film is not universal and it is too early to determine whether the film formulation has had the desired effect on unintentional exposure among children. The nature of the film cannot mitigate misuse, noncompliance, and diversion.

\section{Commentary}

\section{Implications for clinical practice in regions with established addiction treatment}

Although only a few really promising medications for opioid addiction are likely to be approved in the near term, there is some cause for celebrating those developments as significant. Lofexidine will be a valuable medication if it proves out as a workable means of alleviating withdrawal symptoms, accomplished with fewer side effects than clonidine, the medication for opioid detoxification more commonly used in the US. Getting addicts into treatment may be much easier given the prospect of a less grueling detoxification with withdrawal symptoms well controlled by a lofexidine regimen of several days. Even then, lofexidine for managing opioid withdrawal symptoms would not likely displace buprenorphine as a means of assisting detoxification except in cases where patients and clinicians eschew opioids, even a partial opioid agonist. For those patients who are willing to remain on a partial opioid agonist (as in substitution therapy) or who have been unable to adhere to an antagonist protocol, Probuphine (buprenorphine implant) offers a distinctive new formulation of a proven medication that would appear to relieve patients, clinicians, and regulatory personnel from the burden of diversion, misuse, and unintended exposure in children.

An implantable or injectable depot formulation of an effective medication might be considered an optimum approach, considering the resulting negation of medication nonadherence, misuse, and diversion, but this may not be an opinion shared by some addiction medicine clinicians and patients. Those who are familiar with the initial efforts to use depot naltrexone as an opioid addiction treatment can be forgiven for not being early enthusiasts of Probuphine, despite its apparent advantages. Their recollections are dominated by the almost universal difficulties in attracting individuals to the antagonist medication, which is understandable, given the fact that patients disliked taking the oral medication and were leery of a long-acting form. This is not the case with buprenorphine, being a partial agonist. Instead, the converse problem arose with sublingual buprenorphine, which can happen when patients like their medication too much, or when they provide portions of their dosage to acquaintances. Ensuing problems arise with diversion, misuse, and unintended exposure resulting in accidental poisoning. Probuphine was designed to address these problems, but the medication must proceed through the regulatory approval process, involving extensive research. A recent publication in October 2010 was a major step in that direction, documenting the effectiveness of Probuphine, thus offering a means to curtail the problems of adherence, diversion, misuse, and accidental poisoning associated with sublingual buprenorphine. ${ }^{23}$

Many clinicians and prospective patients have high expectations of Probuphine, just as they did for buprenorphine. Such potential can be hard to live up to; in the short run, Probuphine must continue through the approval gauntlet and ultimately be tested in community-based practice with real patients before its "success" is confirmed. The steady progress in development continues, and the manufacturer (Titan Pharmaceuticals, Brooklyn, NY) is expected to file a New Drug Application soon. Eventual FDA approval of Probuphine will enable provision of an effective means to counter the problems of medication adherence, diversion, and accidental poisoning associated with sublingual buprenorphine.

Depot delivery of medications has always been controversial, so the continued debate about depot naltrexone is not surprising. Announcement of FDA approval of Vivitrol and release of supportive research documentation sparked a heated debate in the literature and among clinicians around the world, raising such issues as potential overdose among Vivitrol-treated individuals who use opioids soon after the antagonist effects wane following cessation, and a possible range of side effects that could inhibit patients' willingness to comply with subsequent Vivitrol injections. The Russian trial (which was the basis for FDA approval of Vivitrol) indicated a generally good tolerability and retention in treatment, and the results would not categorically be considered inapplicable to other opioid addicts. Still, the findings should be replicated in locales where patients have other options for treatment, including opioid agonist and partial agonist medications. Research has not been conducted to inform which patient populations may be best suited to long-term antagonist treatments, though some highly motivated subpopulations such as physicians have had good clinical outcomes with long-term treatment with oral naltrexone. The availability of sustained-release 
naltrexone should facilitate such long-term treatment but it is too early to know this from current research.

\section{Implications regarding HIV among opioid-using populations}

A particularly important aspect of buprenorphine is its compatibility with HIV antiretroviral therapies. The literature indicates fewer interactions between buprenorphine and HIV medications than have been documented with methadone and HIV medications. ${ }^{60,61}$ Although interactions between buprenorphine and some HIV/AIDS medications do have the potential to alter buprenorphine levels, the effects do not appear clinically significant for most of the HIV medications. Monitoring buprenorphine dose levels in the presence of such medications is advised in Treatment Improvement Protocol Series 40. ${ }^{62}$ Buprenorphine is the preferred medication for comorbid opioid dependence and HIV/AIDS, given the ability of a treating clinician to care medically for an HIV-infected patient and also prescribe the less restricted partial agonist therapy. The Probuphine form of buprenorphine offers additional benefits in this regard, where its ensured delivery over an extended period can help stem opioid use that involves behaviors that increase risk of HIV transmission. Similarly, Vivitrol can be considered an important medication advance in the struggle to halt transmission of HIV, because its monthlong effect helps reduce opioid use and related risky behaviors. The promotion of addiction medications in developing countries as a means of helping to curtail HIV/AIDS is particularly important, as noted below.

\section{Implications for implementation of addiction treatment in developing regions}

In the Western "first world" nations, the development of new pharmacotherapies and improvements to current opioid addiction treatments are natural steps toward more efficient, more effective, and more palatable approaches to treating addiction. In contrast, the developing countries are in many cases completely lacking in addiction treatment infrastructure, having very little clinical experience with medications and logistics of addiction treatment. Thus, some of the innovations in medications that have been long used in most European and North American nations could be considered "new" therapies that might be usable by clinicians in the countries lacking previous expertise with the older pharmacotherapies such as methadone and naltrexone. Such a "leapfrogging" of older therapies may be feasible in countries with supportive contextual features, such as China, with a large national health system. Nations with limited resources and with few clinicians familiar with addiction treatment of any kind may need to progress through the traditional steps of implementing early-version medications before being able to make use of the newly developed pharmacotherapies.

An important consideration regarding treatment of opioid addiction in the developing countries is the high rate of HIV/ AIDS among addicts, which means that clinicians must be increasingly concerned with potential drug/drug interactions involving antiretroviral agents and addiction medications. In many areas, such as China, methadone is the primary or only addiction medication that is available thus far, and methadone can be a problem in the presence of HIV/AIDS pharmacotherapies. As noted above, buprenorphine would be the preferred addiction medication, but regulatory circumstances and political policies may preclude adoption of the partial agonist due to its potential for misuse, diversion, and noncompliance.

Conceivably, a superior medication that can be safely used in conjunction with HIV/AIDS pharmacotherapies would prevail, but in the case of countries with long-standing policies against opioid "substitution" such as with methadone or buprenorphine, resistance to buprenorphine may persist. The anticipated availability of Probuphine represents an attractive alternative that should be palatable to most cultures. In places where even Probuphine might be rejected, such as where "therapy" for opioid addiction is limited to long-term forced abstinence in labor camps or "rehabilitation centers," Vivitrol may be the useful pharmacotherapy to prevent relapse to opioid use after such "treatment".

\section{Summary}

The problem of opioid addiction will not go away on its own, and treatments must continue to be developed and made workable and cost-effective for a range of circumstances and for a variety of addict populations. Some developing countries may become the early adopters of innovative pharmacotherapies sooner than some Western nations if such approaches can be proven effective, thereby enabling bypassing older medications that never gained a foothold as they did in the West. Meanwhile, researchers and clinicians around the world must keep advancing the science and practice to improve what we have while looking toward the horizon for new discoveries and developments in pharmacotherapy, behavioral therapy, and neuroimmunology.

While such research and practice improvement efforts continue, controversies and concerns will emerge in tandem with advances. Reluctance to adopt and implement new medications and procedures can be expected, and expressions 
of caution are important considerations in the regulatory process and in the course of implementation. Best practices and optimized outcomes will emerge from continued development efforts that take into account input from the full range of stakeholders.

\section{Acknowledgments}

The preparation of this article was supported in part by a National Institute on Drug Abuse grant to WL (U10 DA 013045 Clinical Trials Network Pacific Region Node) and a National Institute on Drug Abuse INVEST/Clinical Trials Network fellowship to SN.

\section{Disclosure}

WL has received unrestricted education grants from Reckitt/ Benckiser and research support from Reckitt/Benckiser and Hythiam Inc, and has also served as an occasional consultant to Reckitt/Benckiser, Titan Pharmaceuticals, US World Med Inc, Alkermes, and DemeRx. MT has in the past participated in the Reckitt/Benkiser "treatment advocate" program. SN has in the past worked on an unrestricted educations grant from Reckitt/Benckiser. KM has received an honorarium from Reckitt/Benckiser. The other authors have no disclosures to report.

\section{References}

1. Krupitsky EM, Blokhina EA. Long-acting depot formulations of naltrexone for heroin dependence: a review. Curr Opin Psychiatry. 2010;23(3):210-214.

2. Gowing L, Ali R, White J. Buprenorphine for the management of opioid withdrawal. Cochrane Database Syst Rev. 2006;19(2):CD002025.

3. Gowing L, Farrell M, Ali R, White JM. Alpha2-adrenergic agonists for the management of opioid withdrawal. Cochrane Database Syst Rev. 2009;15(2):CD002024.

4. Gish EC, Miller JL, Honey BL, Johnson PN. Lofexidine, an \{alpha\}2receptor agonist for opioid detoxification. Ann Pharmacother. 2010; 44(2):343-351.

5. Strang J, Bearn J, Gossop M. Lofexidine for opiate detoxification: review of recent randomised and open controlled trials. Am J Addict 1999;8(4):337-348.

6. Lin SK, Strang J, Su LW, Tsai CJ, Hu WH. Double blind randomized controlled trial of lofexidine versus clonidine in the treatment of heroin withdrawal. Drug Alcohol Depend. 1997;48(2):127-133.

7. Yu E, Miotto K, Akerele E, et al. A Phase 3 placebo-controlled, double-blind, multi-site trial of the alpha-2-adrenergic agonist, lofexidine, for opioid withdrawal. Drug Alcohol Depend. 2008;97(1-2): $158-168$.

8. Handelsman L, Cochrane KJ, Aronson MJ, Ness R, Rubinstein KJ, Kanof PD. Two new rating scales for opiate withdrawal. Am J Alcohol Abuse. 1987;13(3):293-308.

9. Wesson DR, Ling W. The Clinical Opiate Withdrawal Scale (COWS). J Psychoactive Drugs. 2003;35(2):253-259.

10. Tompkins DA, Bigelow GE, Harrison JA, Johnson RE, Fudala PJ, Strain EC. Concurrent validation of the Clinical Opiate Withdrawal Scale (COWS) and single-item indices against the Clinical Institute Narcotic Assessment (CINA) opioid withdrawal instrument. Drug Alcohol Depend. 2009;105(1-2):154-159.
11. Fiellin DA, O'Connor PG. New federal initiatives to enhance the medical treatment of opioid dependence. Ann Intern Med. 2002;137(8): 688-692.

12. Amass L, Kamien JB, Mikulich SK. Efficacy of daily and alternate-day dosing regimens with the combination buprenorphine-naloxone tablet. Drug Alcohol Depend. 2000;58(1-2):143-152.

13. Copenhaver M, Bruce R, Altice F. Behavioral counseling content for optimizing the use of buprenorphine for treatment of opioid dependence in community-based settings: a review of the empirical evidence. $A m J$ Drug Alcohol Abuse. 2007;33(5):643-654.

14. Fiellin DA, Rosenheck RA, Kosten TR. Office-based treatment for opioid dependence: reaching new patient populations. Am J Psychiatry. 2001;158(8):1200-1204.

15. Fudala PJ, Bridge TP, Herbert S, Chiang CN, Leiderman DB. The Buprenorphine/Naloxone Collaborative Study Group. A multisite efficacy evaluation of a buprenorphine/naloxone product for opioid dependence treatment. NIDA Research Monograph 179. Rockville, MD: DHHS/NIH/NIDA; 1998.

16. Ling W, Wesson DR, Charuvastra C, Klett CJ. A controlled trial comparing buprenorphine and methadone maintenance in opioid dependence. Arch Gen Psychiatry. 1996;53(5):401-407.

17. Ling W, Wesson DR. Clinical efficacy of buprenorphine: comparisons to methadone and placebo. Drug Alcohol Depend. 2003;70(2 Suppl): S49-S57.

18. Amass L, Ling W, Freese TE, et al. Bringing buprenorphine-naloxone detoxification to community treatment providers: The NIDA Clinical Trials Network field experience. Am J Addict. 2004;13(Suppl 1): S42-S66.

19. Compton PA, Wesson DR, Charuvastra VC, Ling W. Buprenorphine as a pharmacotherapy for opioid addiction. What dose provides a therapeutic response? Am J Addict. 1996;5:220-222.

20. Fudala PJ, Bridge TP, Herbert S, et al. Office-based treatment of opioid addiction with a sublingual-tablet formulation of buprenorphine and naloxone. N Eng J Med. 2003;349(10):949-958.

21. SAMHSA (Substance Abuse and Mental Health Services Administration). SAMHSA/CSAT Buprenorphine Information Center, 2010. Available from: http://buprenorphine.samhsa.gov/faq.html. Accessed Jul 2011.

22. Titan Pharmaceuticals. Investigator's Brochure. Confidential research protocol documentation. June 21, 2008.

23. Ling W, Cassdonte P, Bigelow G, et al. Buprenorphine implants for treatment of opioid dependence: a randomized controlled trial. JAMA. 2010;304(12):1576-1583.

24. Titan Pharmaceuticals. Press Release: Titan Pharmaceuticals Announces Positive Top Line Results In Confirmatory Phase 3 Trial Of Probuphine. May 16, 2011. Accessed from: http://www.titanpharm.com/press/110816phase3-probuphine-positive-results.htm. Accesed 13 September, 2011.

25. Gonzalez JP, Brogden RN. Naltrexone: A review of its pharmacodynamic and pharmacokinetic properties and therapeutic efficacy in the management of opioid dependence. Drugs. 1988;35(3):192-213.

26. Gonzalez G, Oliveto A, Kosten TR. Combating opiate dependence: a comparison among the available pharmacological options. Expert Opin Pharmacother. 2004;5(4):713-725.

27. Judson BA, Carney TM, Goldstein A. Naltrexone treatment of heroin addiction: efficacy and safety in a double-blind dosage comparison. Drug Alcohol Depend. 1981;7(4):325-346.

28. Judson BA, Goldstein A. Naltrexone treatment of heroin addiction: one-year follow-up. Drug Alcohol Depend. 1984;13(4): 357-365.

29. Martin WR, Jasinski DR, Mansky PA. Naltrexone, an antagonist for the treatment of heroin dependence. Effects in man. Arch Gen Psychiatry. 1973;28(6):784-791.

30. Modesto-Lowe V, Van Kirk J. Clinical uses of naltrexone: a review of the evidence. Exp Clin Psychopharmacol. 2002;10(3):213-227.

31. Minozzi S, Amato L, Vecchi S, Davoli M. Maintenance agonist treatments for opiate dependent pregnant women. Cochrane Database Syst Rev. 2008;16(2):CD006318. 
32. (NoAuthor). Clinical evaluation of naltrexone treatment of opiate-dependent individuals. Report of the National Research Council Committee on Clinical Evaluation of Narcotic Antagonists. Arch Gen Psychiatry. 1978;35(3):335-340

33. Rounsaville BJ. Can psychotherapy rescue naltrexone treatment of opioid addiction? NIDA Res Monogr. 1995;150:37-52.

34. Hollister L, Schwinn R, Kasper P. Naltrexone treatment of opiatedependent persons. Drug Alcohol Depend. 1977; 2(3):203-209.

35. Digiusto E, Shakeshaft A, Ritter A, O'Brien S, Mattick RP; NEPOD Research Group. Serious adverse events in the Australian National Evaluation of Pharmacotherapies for Opioid Dependence (NEPOD). Addiction. 2004;99(4):450-460. Erratum in: Addiction. 2005;100(1):139.

36. Gibson AE, Degenhardt LJ, Hall WD. Opioid overdose deaths can occur in patients with naltrexone implants. Med J Aust. 2007;186(3):152-153.

37. Ritter AJ. Naltrexone in the treatment of heroin dependence: relationship with depression and risk of overdose. Aust $N Z J$ Psychiatry. 2002;36(2):224-228.

38. Brahen LS, Henderson RK, Capone T, Kordal N. Naltrexone treatment in a jail work-release program. J Clin Psychiatry. 1984;45(9 Pt 2): 49-52.

39. Cornish JW, Metzger D, Woody GE, et al. Naltrexone pharmacotherapy for opioid dependent federal probationers. J Subst Abuse Treat. 1997;14(6):529-534.

40. Ling W, Wesson DR. Naltrexone treatment for addicted health care professionals: a collaborative private practice experience. J Clin Psychiatry. 1984;45(9 Pt 2):46-48.

41. Washton AM, Gold MS, Pottash AC. Successful use of naltrexone in addicted physicians and business executives. Adv Alcohol Subst Abuse. 1984;4(2):89-96.

42. Anton RE, Hogan I, Jalali B, Riordan CE, Kleber HD. Multiple family therapy and naltrexone in the treatment of opiate dependence. Drug Alcohol Depend. 1981;8(2):157-168.

43. Resnick RB, Washton AM, Stone-Washton N. Psychotherapy and naltrexone in opioid dependence. NIDA Res Monogr. 1981;34:109-115.

44. Carroll KM, Ball SA, Nich C, et al. Targeting behavioral therapies to enhance naltrexone treatment of opioid dependence: efficacy of contingency management and significant other involvement. Arch Gen Psychiatry. 2001;58(8):755-761.

45. Preston KL, Silverman K, Umbricht A, DeJesus A, Montoya ID, Schuster CR. Improvement in naltrexone treatment compliance with contingency management. Drug Alcohol Depend. 1999;54(2):127-135.

46. Comer SD, Collins ED, Kleber HD, Nuwayser ES, Kerrigan JH, Fischman MW. Depot naltrexone: long-lasting antagonism of the effects of heroin in humans. Psychopharmacology (Berl). 2002;159(4): 351-360.

47. Comer SD, Sullivan MA, Walker EA. Comparison of intravenous buprenorphine and methadone self-administration by recently detoxified heroin-dependent individuals. J Pharmacol Exp Ther. 2005; 315(3):1320-1330.

48. Comer SD, Sullivan MA, Yu E, et al. Injectable, sustained-release naltrexone for the treatment of opioid dependence. Arch Gen Psychiatry. 2006;63(2):210-218.

49. Hulse GK, Arnold-Reed DE, O’Neil G, Chan CT, Hansson RC. Achieving long-term continuous blood naltrexone and 6-beta-naltrexol coverage following sequential naltrexone implants. Addict Biol. 2004;9(1):67-72.

Substance Abuse and Rehabilitation

\section{Publish your work in this journal}

Substance Abuse and Rehabilitation is an international, peer-reviewed, open access journal publishing original research, case reports, editorials, reviews and commentaries on all areas of addiction and substance abuse and options for treatment and rehabilitation. The manuscript management system is completely online and includes a very quick and fair
50. Hulse GK, Arnold-Reed DE, O’Neil G, Chan CT, Hansson R, O’Neil P. Blood naltrexone and 6-beta-naltrexol levels following naltrexone implant: comparing two naltrexone implants. Addict Biol. 2004;9(1):59-65.

51. Olsen L, Christophersen AS, Frogopsahl G, Waal H, Mørland J. Plasma concentrations during naltrexone implant treatment of opiate-dependent patients. Br J Clin Pharmacol. 2004;58(2):219-222.

52. Colquhoun R, Tan DY, Hull S. A comparison of oral and implant naltrexone outcomes at 12 months. J Opioid Manag. 2005;1(5):249-256.

53. Carreño JE, Alvarez CE, Narciso GI, Bascarán MT, Díaz M, Bobes J. Maintenance treatment with depot opioid antagonists in subcutaneous implants: an alternative in the treatment of opioid dependence. Addict Biol. 2003;8(4):429-438.

54. Garbutt JC, Kranzler HR, O’Malley SS, et al. Efficacy and tolerability of long-acting injectable naltrexone for alcohol dependence. JAMA. 2005;293:1617-1625.

55. Johnson BA, Ait-Daoud N, Aubin HJ, et al. A pilot evaluation of the safety and tolerability of repeat dose administration of long-acting injectable naltrexone (Vivitrex) in patients with alcohol dependence. Alcohol Clin Exp Res. 2004;28(9):1356-1361.

56. Roozen HG, DeWaart R, VanDenBrink W. Efficacy and tolerability of naltrexone in the treatment of alcohol dependence: oral versus injectable delivery. Eur Addict Res. 2007;13(4):201-206.

57. Substance Abuse and Mental Health Services Administration (SAMHSA). Drug Abuse Warning Network (DAWN), National Estimates of Drug-Related Emergency Department Visits, 2004-2009. Available from: http://dawninfo.samhsa.gov/data/ed/Nation/Nation_2009_Illicit. xls. Accesed 13 September, 2011.

58. Pedapati E, Bateman ST. Toddlers requiring pediatric intensive care unit admission following at-home exposure to buprenorphine/naloxone. Pediatr Crit Care Med. 2011;12(2):e102-e107.

59. Suboxone Sublingual Film [package insert]. Richmond, VA: Reckitt Benckiser Pharmaceuticals Inc; 2010

60. Carrieri MP, Vlahov D, Dellamonica P, et al. Use of buprenorphine in HIV-infected injection drug users: negligible impact on virologic response to HAART. The Manif-2000 Study Group. Drug Alcohol Depend. 2000;60(1):51-54.

61. McCance-Katz EF, Sullivan LE, Nallani S. Drug interactions of clinical importance among the opioids, methadone and buprenorphine, and other frequently prescribed medications: a review. Am J Addict. 2009;19(1):4-16

62. Center for Substance Abuse Treatment. Clinical guidelines for the use of buprenorphine in the treatment of opioid addiction. Treatment Improvement Protocol (TIP) Series 40. DHHS Publication No. (SMA) 04-3939. Rockville, MD: Substance Abuse and Mental Health Services Administration; 2004. Available from: http://www.naabt.org/links/ TIP_40_PDF.pdf. Accessed Oct, 2011. 